\title{
Concepções alternativas e ensino de biologia: como utilizar estratégias diferenciadas na formação inicial de licenciandos em biologia*
}

\author{
Silmara Sartoreto de Oliveira** \\ Fernando Bastos ${ }^{* * *}$
}

Artículo recibido: 12-02-2006 y aprobado: 26-04-2006

Resumo: O presente trabalho objetivou investigar como as aulas de histologia do Curso de Ciências Biológicas se desenvolvem no que se refere ao difícil aprendizado dos alunos sobre o conceito científico relacionado à "Tecido Muscular".Para a avaliação,optou-se pela investigação das concepções alternativas dos alunos a respeito da estrutura e função da fibra muscular e para tanto, iniciou-se por uma entrevista para avaliar as dificuldades de aprendizagem apresentadas pelos mesmos. Os resultados desta entrevista orientaram a organização de um questionário a ser aplicado aos alunos.

\begin{abstract}
Alternative conceptions and biology teaching: how to use differentiated strategies in the initial formation of graduated in biology
\end{abstract}

Palavras-chave: Concepções alternativas, análise, estratégias de ensino.

Abstract: This work was aimed at describing how the histology classes in a biological course were developed, regarding to the difficult learning of scientific concepts about muscular tissues. To do this, students' conceptions on structure and function of muscular fibers were considered. First, an interview was applied to find students' learning difficulties and then, based on those results, a questionnaire was designed and applied in order to einforce the findings.

Key words: Alternative conceptions, diagnosis, teaching strategies.

Este trabalho faz parte da Dissertação de Mestrado apresentada junto ao Programa de Pós-Graduação em Educação Para a Ciência, da Faculdade de Ciências - UNESP/ Campus de Bauru. Grupo Pesquisa em Ensino de Ciências sartoret@fc.unesp.br

** Doutoranda em Educação para a Ciência Faculdade de Ciências - Unesp/Bauru. Grupo em Ensino de Ciências. fernando_bastos2005@ig.com.br

*** Docente do Programa de Pós-Graduação em Educação para a Ciência Faculdade de Ciências - Unesp/Bauru. 


\section{Introdução}

Este trabalho surgiu, devido às dificuldades que os alunos do primeiro ano do Curso de Licenciatura em Ciências Biológicas da UNESP, do Campus de Bauru apresentavam sobre o conteúdo científico referente a "Tecido Muscular". Os alunos que freqüentavam a disciplina de Histologia, que desenvolvia o referente conteúdo, mostravam certa confusão, quanto à denominação das partes que compunham o "Tecido Muscular".

Após o contato com toda esta terminologia, nas aulas teóricas e práticas, os alunos eram novamente questionados, tempos mais tarde, sobre o mesmo conteúdo, em disciplinas co-relacionadas, e mais uma vez apresentavam confusão na denominação da estruturação muscular. Atribuía-se então, a este fato, a falta de interesse e motivação na aprendizagem, ou ainda, à dificuldade de visualização das estruturas do "Tecido Muscular".

Sendo assim, procurou-se desenvolver um trabalho que suprisse essa necessidade, levando em consideração as concepções alternativas dos alunos no referente tópico relacionado ao conhecimento científico "Tecido Muscular".

O conhecimento das concepções alternativas dos alunos é fato de grande importância para o planejamento das atividades pedagógicas, uma vez que as idéias dos estudantes sobre as estruturas biológicas muitas vezes não coincidem com o contexto cientificamente aceito (Bastos, 1991).

A parte experimental deste trabalho inclui uma entrevista prévia com os alunos para uma avaliação geral das reais dificuldades, o que permitiu um aprimoramento das principais necessidades a serem investigadas. Em seguida apli- cou-se um questionário com questões abertas, onde os alunos descrevessem os conceitos sobre a fibra muscular. Sendo assim, com essas duas etapas de investigação, obteve-se uma análise dos conteúdos prévios trazidos pelos alunos, para determinar o melhor instrumento de avaliação das concepções dos alunos sobre o conteúdo específico.

O objetivo deste trabalho foi analisar as dificuldades de aprendizagem apresentadas pelos alunos sobre o conteúdo específico "Tecido Muscular". Com isso propor uma estratégia alternativa de ensino para as disciplinas que compõem o Curso de Biologia.

As pesquisas em educação têm se preocupado com a análise das concepções alternativas dos alunos, uma vez que a aprendizagem escolar é influenciada pelo que o aluno já sabe, e principalmente, pelo fato das concepções alternativas não coincidirem com o cientificamente aceita (Simpson y Arnold, 1982).

Diante deste ponto de vista, decidiuse investigar as principais dificuldades que os alunos apresentam sobre o conteúdo específico "Tecido Muscular", tomando por base as concepções alternativas que os alunos trazem para a sala de aula.

\section{Concepções Alternativas}

Os dois grandes teóricos Piaget e Ausubel, segundo Santos (1998), são considerados precursores do Movimento das Concepções Alternativas (MCA). Embora precursores, possuem alguns pontos comuns e outros divergentes. Ambos defendem que é o sujeito, com suas ações, que irá determinar a organização e estruturação de seu conhecimento. 
O sujeito é parte ativa do processo de desenvolvimento da estrutura irá determinar a organização e estruturação de seu conhecimento e é parte ativa do processo de desenvolvimento da estrutura cognitiva. Ele é parte atuante e essencial no processo de construção do conhecimento. Portanto, deve-se considerar sua visão acerca do mundo, pois é ele o alvo de interesse neste processo. Sem sua participação efetiva, a construção dos conceitos não ocorre, portanto, não ocorre aprendizagem, somente transmissão de conhecimentos que se apresentam desvinculados da realidade.

As concepções acerca do mundo são construídas pelos alunos a partir do seu nascimento e o acompanham também em sala de aula, onde os conceitos científicos são inseridos sistematicamente no processo de ensino e aprendizagem. Essas concepções são caracterizadas por carregarem uma grande conotação simplista como forma de explicar os fenômenos ou preceitos científicos. $\mathrm{Na}$ visão de Pozo (1998), tais concepções são caracterizadas como construções pessoais dos alunos que foram elaboradas de forma espontânea com a interação desses alunos com o meio ambiente em que vivem e com as outras pessoas. Para o autor, a utilização das concepções alternativas em sala de aula, visa organizar e dar sentido as diversas situações de ensino e conteúdos a serem ministrados.

Para caracterizar as concepções que os alunos constroem, e transformá-las em preceitos científicos em sala de aula, são utilizadas diferentes conotações na visão de vários autores, como: idéias intuitivas (Driver, 1986), pré-concepções (Gil Pérez, 1986; Freitas y Duarte,
1990), idéias prévias (Gil Pérez, 1986; Driver, 1988), pré-conceitos (Novak, 1977; Andersson, 1986), erros conceituais (Linke y Venz, 1979), conceitos alternativos (Gilbert, 1982), conhecimentos prévios (Pozo, 1998) e por fim, concepções alternativas (Santos, 1998). Neste trabalho adotaremos o termo concepções alternativas descrito por Santos (1998), pois assim como a Autora, este termo indica a forma como os teóricos e investigadores do Movimento das Concepções Alternativas apontam Piaget e Ausubel como precursores desta linha de investigação.

Estes termos acima citados refletem posições epistemológicas diferentes, mas com algo em comum: cada aluno leva para a sala de aula estrutura cognitiva própria, elaborada a partir de suas experiências diárias que servem para explicar e predizer o que ocorre a sua volta. Portanto, consideramos o termo "concepções alternativas" o mais adequado a ser utilizado dentre os trabalhos dos autores consultados nesta pesquisa.

Mortimer (2000) acredita que o ensino efetivo em sala de aula depende também de um elemento facilitador representado pelo professor. Neste caso o professor propicia aos alunos situações sobre o conteúdo, que possam utilizar suas concepções alternativas. O mais importante no processo de ensino e aprendizagem são as etapas de construção do conhecimento percorridas por professores e alunos.

\section{Estratégia de Ensino Proposta}

A utilização das concepções alternativas no processo de ensino em sala de aula está relacionada com a resistência à 
mudança dessas concepções por parte dos alunos. Este fato é observado em conteúdos que não apresentam, na visão do aluno, domínio de aplicação. Os conteúdos são normalmente ministrados levando em consideração a generalidade, ou seja levam em consideração o conteúdo de forma específica, torna-os muito teóricos e pouco práticos para os alunos (Pozo, 1998).

Levando em consideração as concepções alternativas dos alunos, pretendese aqui, apresentar uma estratégia alternativa de ensino que pode ser utilizada na sala de aula para inserir conteúdos científicos referentes à "Tecido Muscular". Sendo assim, a inserção de uma situação problema em sala de aula poderá estimular o aluno sobre a aprendizagem de um novo conteúdo e ao mesmo tempo permitir ao professor investigar os problemas apresentados em sala de aula. Pozo (1998) defende a utilização de uma situação problema onde os alunos possam explicar, com detalhes, situações óbvias e cotidianas. A finalidade desta atividade é propiciar a elucidação das concepções alternativas dos alunos, relacionando-as ao conteúdo científico inserido em sala de aula.

Definidos os conceitos, baseados na situação problema, o professor poderá ainda utilizar um modelo de ensino que facilite a visualização sobre o novo conteúdo e, conseqüentemente, o processo de ensino e aprendizagem de seus alunos. Portanto, poderá propor a construção de um modelo tridimensional da "Fibra Muscular" (uma maquete) pelos alunos, como forma de reforçar na prática a constituição e funcionamento da célula muscular.
Ao mesmo tempo, através da aula prática, com a observação de lâminas e fotos em microscopia eletrônica, o professor poderá fornecer aos alunos situações onde possam comparar estruturas apontadas por eles na maquete, com as fotos apresentadas nos livros didáticos.

Com a finalidade de averiguar as concepções alternativas dos alunos sobre o referido conteúdo, propõemse duas alternativas, ou métodos, que o professor poderá utilizar em sala de aula. É importante definir os objetivos que se deseja alcançar com cada uma das atividades propostas. Estes objetivos deverão ser expostos aos alunos no decorrer das atividades, para que possam participar e compreender a intenção de cada atividade.

Com os objetivos claramente expostos, o professor poderá, portanto, utilizar estratégias para conseguir definir quais as principais dificuldades apresentadas pelos alunos. Com este objetivo, poderá propor uma entrevista inicial, trabalhando com alunos individualmente ou em grupos formados ao acaso. Quem irá definir a disposição desses alunos, será o professor, dependendo do número de alunos em sala de aula. Se a sala de aula for constituída por um grande número de alunos, sugere-se que o professor trabalhe com pequenos grupos (quatro alunos) para facilitar o seu monitoramento. Porém, se a sala constituir-se de poucos alunos, nesta etapa seria melhor trabalhar com alunos individualmente, assim, o professor terá um análise dos problemas individuais levantados pelos alunos e, trabalhando com grupos, o professor deverá considerar as dificuldades apontadas pelos 
grupos. O professor poderá utilizar recursos áudio visuais como forma de obtenção das respostas emitidas por cada aluno. Estes recursos deverão ser cuidadosamente utilizados para não causar constrangimento entre os alunos e, conseqüentemente, não interferir nas suas respostas. Também poderá utilizar atividades na forma escrita, onde os alunos terão que responder a esta atividade com suas concepções alternativas.

Independente da estratégia adotada, para verificar qual o nível de conhecimento que os alunos trazem para a sala de aula, o professor deverá elaborar um roteiro de atividades, através da inserção de um problema que faz parte do cotidiano do aluno. Este problema deverá abordar indiretamente os aspectos mais importantes sobre o conteúdo e, ao mesmo tempo, fazer com que o conteúdo seja compatível com o grau de conhecimento em que o aluno se encontra.

Com a aplicação dessa situação problema em sala de aula, o professor deverá analisar as respostas obtidas pela estratégia utilizada (entrevista ou atividade escrita) para assim definir os aspectos mais importantes que deverão ser abordados em sala de aula durante a aula teórica e prática.

A segunda etapa da estratégia de ensino aqui abordada se refere à aula teórica. Nesta aula, o professor tem o papel norteador dos conceitos comuns aos conceitos cientificamente postulados. Propõe-se que ao iniciar a aula teórica, o professor insira o conteúdo, através de diálogos com toda a sala, ao mesmo tempo lance questionamentos entre os alunos, favorecendo pequenas discussões em sala de aula.
A atividade proposta propiciam situações de interação entre professores e alunos, no processo de ensino e aprendizagem em sala de aula. Para que esta situação efetivamente ocorra, o professor deverá elaborar cuidadosamente as questões que poderão ser lançadas aos alunos, mediante as respostas obtidas com a situação problema apresentada na entrevista.

Ao final da aula teórica, o professor deverá relembrar os alunos da situação problema que antes se apresentara sem solução. Assim, os próprios alunos irão resgatar este problema antes que o professor o faça.

Na terceira etapa desta estratégia de ensino utilizada em sala de aula, é proposto que o professor insira uma atividade prática aos seus alunos. Neste momento, o professor deverá propor aos seus alunos a construção de uma maquete, com a utilização de sucatas e materiais recicláveis (barbante, papelão, canudos, lãs, isopor, papéis coloridos) enfim, todo o tipo de material que o aluno conseguir reunir. Com isso, o professor poderá abordar conceitos que fazem parte de outras disciplinas, mostrando ainda que seja possível trabalhar com o conteúdo abordado de forma interdisciplinar.

O professor, nesta etapa tem o papel de motivar e ao mesmo tempo ressaltar os conceitos científicos que serão questionados pelos alunos no momento da construção da maquete.

$\mathrm{O}$ aspecto mais importante a ser abordado nesta etapa é a compreensão dos alunos no que se refere àqueles aspectos apontados pela entrevista, que neste trabalho foram definidos pelo formato e, a disposição e função das 
organelas na célula muscular. Portanto, o professor deve manter-se atento as concepções dos alunos, que deverão ser abordadas na construção da maquete.

O término da construção desta maquete aponta para a quarta e última atividade proposta nesta estratégia, que será a aula prática com a visualização de lâminas histológicas e fotografias de microscopia eletrônica. Esta quarta atividade deverá possibilitar ao aluno visualizar as estruturas e organelas que constituem o "Tecido Muscular". Este fato se torna importante, na medida em que esses alunos poderão ao mesmo tempo comparar estas estruturas com aquelas apontadas na maquete.

\section{Pressupostos Teóricos da Estratégia Proposta}

Mortimer (2000) utilizou estratégias diferenciadas do ensino tradicional empregue usualmente em sala de aula. Trabalhou com alunos no campo da física, elaborando uma atividade em sala de aula, composta por uma situação problema.

$\mathrm{O}$ autor investigou a formação de conceitos de física com alunos do ensino médio (dispostos em grupos) através da apresentação de um problema. Neste estudo, os alunos tiveram que descrever sobre um problema elaborado a partir dos "modelos da existência de ar na seringa", como forma de discussão nos grupos. Nesta proposta, Mortimer instiga seus alunos a defender suas concepções mediante ao modelo proposto. Este fato permitiu ao autor planejar esta atividade de acordo com o que denomina de "zonas iniciais do perfil do átomo", proposto a esses alunos (Mortimer, 2000).
Mortimer nos propõe uma estratégia, onde as concepções dos alunos são analisadas através de uma situação problema perturbadora, com o intuito de fazer com que os alunos busquem em suas concepções alternativas, respostas para tal problema. Além disso, esta situação também motiva o professor a buscar estratégias alternativas que estejam baseadas na realidade dos alunos. Neste caso, os professores devem considerar as concepções alternativas apresentadas pelos alunos como ponto de partida para a aquisição de novos conceitos. Este fato permite uma maior integração entre a teoria e a prática (Mortimer, 2000).

Na utilização de técnicas em sala de aula, como questionários, entrevistas e apresentação de situação problema para a inserção de um novo assunto, Pozo (1998) postula que tais atividades nos levam a:

1. Conhecer as principais concepções alternativas dos alunos sobre o assunto a ser abordado, o que irá auxiliar na elaboração das atividades em sala de aula;

2. Fornecer aos alunos situações que propiciem o conhecimento de suas próprias concepções alternativas;

3. Propiciar discussões entre os alunos, favorecendo a interação entre as concepções alternativas.

Analisando a proposta de Mortimer (2000), sobre os conceitos em física, procurou-se adaptar esta idéia na área das Ciências Biológicas sobre o conteúdo "Tecido Muscular". Optou-se pela elaboração de uma estratégia de ensino que abordasse a inserção de um problema como forma de instigar e incentivar os alunos às atividades decorrentes em sala de aula. Seguindo os pressupostos 
de Mortimer, procurou-se adaptar sua pesquisa em um conteúdo específico de biologia no nível superior de ensino.

Ao inserir uma atividade que aborde uma situação problema em sala de aula, com o intuito de evidenciar as concepções alternativas dos alunos, temos as atividades baseadas na aprendizagem por descobrimento destacada por Ausubel (apud: Coll et al., 1998). Este tipo de aprendizagem, segundo Joyce e Weil (Coll et al., 1998), deve seguir cinco passos:

1. O aluno deve confrontar-se com esta situação problema de forma surpreendente ou inesperada, tornando-se perturbadora;

2. Mediante a situação proposta, os alunos deverão observar e identificar as variáveis implícitas na situação problema;

3. O aluno deverá testar ou experimentar este problema proposto;

4. Os alunos deverão organizar e interpretar as idéias resultantes da exposição do problema;

5. Com a compreensão da atividade proposta (situação problema), o aluno deverá refletir sobre a estratégia de resolução por ele adotada e sobre os resultados obtidos.

Cabe ressaltar que nem todas as atividades de ensino por descobrimento passam por esses cinco passos, pois depende da idade e da estrutura cognitiva do aluno. As dificuldades apresentadas pela aprendizagem por descoberta estão relacionadas com o grau de complexidade do conteúdo. Este fato nos faz pensar em outra estratégia de ensino, a aula expositiva. Neste caso, a aula expositiva se torna necessária para embasar atividades formuladas a partir da exposição de conteúdos mais complexos (Coll et al., 1998).

A apresentação do conteúdo de forma expositiva, ainda muito utilizada pelos professores, consiste de atividades escritas ou orais. As atividades orais, também utilizadas neste trabalho, devem levar em consideração a ativa cognição do aluno. Este tipo de atividade dirigida para aquisição de novos conceitos, deve seguir três fases, segundo Ausubel (Coll et al., 1998):

1. Ser orientada por um organizador prévio, que seria uma fase introdutória e que teria a função de uma "ponte", ligando as concepções alternativas aos novos conceitos;

2. Apresentar o material a ser utilizado de forma estruturada e com uma linguagem simples;

3. Estabelecer a conexão entre concepções alternativas e o novo conceito, partindo da comparação e exemplificação.

A aula teórica expositiva deverá ser baseada na interação ou mediação do professor com seus alunos. Ao defender a transmissão de conhecimento entre professor e aluno em sala de aula, Ausubel et at. (1980) se refere ao processo de ensino através da aprendizagem receptiva significativa. Neste sentido, aula expositiva se torna um recurso metodológico importante na integração de diferentes assuntos, cabendo ao professor e/ou aos recursos didáticos disponíveis evidenciarem semelhanças e diferenças existentes entre o novo conceito e as concepções alternativas de cada aluno.

A aprendizagem receptiva, com técnicas expositivas, na grande maioria das vezes apresenta o conteúdo aos alunos, 
dissociando-o de fatos e exemplos concretos. Quando o professor utiliza técnicas expositivas combinadas a outros tipos de práticas pedagógicas, poderá favorecer melhor aproveitamento na aquisição dos conceitos, durante o processo de ensino em sala de aula (Ausubel, et at. 1980).

Ausubel defende a presença de um facilitador que possa ajudar os alunos a encontrar meios que o leve à aprendizagem mais significativa, neste caso o professor (Moreira, 1999). A função de norteador dos conceitos científicos, atribuída ao professor, se mostra complexa e de difícil aplicação. Cabe ao professor propiciar situações onde possa reavaliar seus métodos, impulsionar e incentivar seus alunos na aquisição dos novos conceitos. Este novo conhecimento deve ser aplicado nas situações práticas de ensino, com a mediação do professor.

Ao professor cabe organizar, programar e determinar as tarefas a serem utilizadas em sala de aula, para a inserção dos conceitos no auxílio da aprendizagem significativa dos alunos, evitando a aprendizagem memorística. Ausubel defende a aprendizagem significativa por recepção, com certa restrição quanto aos perigos, quando mal utilizada (Madruga, 1996).

\section{A Filosofia Construtivista}

Para fundamentar a utilização de um modelo de ensino em sala de aula, procurou-se na literatura autores que defendem a filosofia construtivista e a evidenciar as visões de alguns desses autores a respeito desta filosofia, inicialmente proposta por Piaget (1971). Ë importante salientar que, por se tratar de uma filosofia muito ampla e explorada, nossa intenção será apresentar algumas idéias dos principais autores consultados no estudo do material bibliográfico presente neste trabalho.

Segundo Gil Pérez (1983) quando o indivíduo consegue construir um significado, reproduzindo o que lhes é ensinado, está participando do processo de construção ativa de seus próprios significados. Neste aspecto, o indivíduo re-elabora suas concepções alternativas para os conceitos pertencentes ao conhecimento científico. Tudo o que é significativo para o indivíduo, passa a fazer parte da sua representação cognitiva nas mais variadas situações. O que é realmente re-elaborado na estrutura cognitiva do indivíduo, passa a fazer parte da elaboração de seus conhecimentos. Portanto, o indivíduo passa a utilizar-se destes conceitos relacionando-os a outras situações em diferentes níveis de interação.

Millar (1989) postula que um modelo baseado na filosofia construtivista de ensino, não tem como seu pressuposto um modelo construtivista de ensino por instrução. Para o Autor, este modelo de ensino consiste em proporcionar maior interação entre a estrutura cognitiva do aluno e a forma (didática) como os conteúdos são inseridos em sala de aula. Esta visão construtivista não deve ser abordada como um único método a ser utilizado pelos profissionais da área educacional.

Em síntese, na visão dos vários autores citados até o presente momento, verifica-se que a concepção construtivista sempre evidencia a interação efetiva entre professor e aluno no processo de ensino. Ao professor cabe o papel 
de nortear as etapas na construção dos conteúdos, e aos alunos a elaboração desses conteúdos mediante a sua cognição (concepções alternativas). As concepções alternativas apresentadas pelos alunos devam ser consideradas como ponto de partida para a compreensão dos preceitos científicos na filosofia construtivista. Portanto seria necessário conhecer as concepções alternativas dos alunos, para assim compreender sua implicação no processo de ensino.

Segundo as idéias de Piaget, para que ocorra aprendizagem, o sujeito terá que transpor seus conflitos, preenchendo as lacunas apresentadas pelo sujeito, pela falta de conhecimento sobre o conteúdo (Piaget, 1977).

Quando o professor propõe uma situação problema ao aluno, e este a considera perturbadora diferente da anterior, acredita-se que houve a instalação do conflito cognitivo proporcionado por essa situação problema. Neste aspecto Mortimer acredita que esta perturbação possibilite ao aluno um aumento de seu conhecimento, propondo a evolução destes conceitos (Mortimer, 1992).

Para Solomon (1983) e Santos (1998), a estratégia de conflito cognitivo pode propiciar Mudança Conceitual. As préconcepções mais resistentes podem continuar a existir, e assim, continuar a ajudar o aluno na compreensão das novas informações que lhes será ensinada.

Mediante a exposição das idéias dos autores, utilizados para a fundamentação da estratégia de ensino proposta, buscou-se também na literatura, autores que trabalharam com estratégias parecidas com a proposta neste trabalho.
Neste sentido Mortimer (2000) nos fornece grande contribuição com sua pesquisa na área da física, com a inserção de uma situação problema perturbadora.

Para fundamentar a utilização da construção de um modelo de ensino, buscou-se utilizar autores que defendam a filosofia construtivista preconizadora do Modelo de Mudança Conceitual (MMC). Sendo assim, Tonolli (2000) nos fornece o embasamento necessário para fundamentar a construção de um modelo tridimensional (maquete) para utilização em sala de aula.

Tonolli (2000) avaliou a evolução conceitual de alunos no ensino superior, abordando a filosofia construtivista de ensino, e das idéias prévias que os alunos traziam do ensino médio. Com este objetivo a autora procurou utilizar uma estratégia de ensino, que facilitasse o processo de ensino e aprendizagem dos alunos envolvidos na pesquisa. Para detectar as dificuldades e as concepções alternativas dos alunos, Tonolli elaborou um questionário com questões de múltipla escolha, que denominou de Pré-Teste.

Ao analisar as concepções alternativas dos alunos, através do pré-teste, Tonolli (2000) propõe juntamente com a aula teórica e prática a construção de um modelo tridimensional de membrana plasmática (maquete), conteúdo específico investigado em seu trabalho. Esta maquete foi apresentada aos alunos como forma de propiciar maior atenção sobre o conteúdo investigado. A isto denominou metodologia alternativa. Em determinadas situações a autora propiciou a instauração de um conflito cognitivo. 
O presente estudo aponta para a necessidade de repensar a prática pedagógica proposta pelo professor em sala de aula, já que alunos e professores estão acostumados ao ensino tradicional. Essas mudanças deveriam iniciar no ensino fundamental, de forma que busquem uma prática pedagógica séria e fundamentada em referenciais que trabalhem com o cotidiano do aluno, vinculando teoria e prática.

\section{Críticas apontadas ao Modelo de Mudança Conceitual}

Um dos principais questionamentos apresentados com o Modelo de Mudança Conceitual proposto por Posner et al., estão relacionados às idéias prévias dos estudantes. A preocupação central sobre este modelo se refere ao abandono ou substituição das concepções alternativas pelos alunos no processo de ensino e aprendizagem. A mudança conceitual, segundo Bastos et al. (2004), permite com que os alunos substituam suas concepções alternativas por outras mais adequadas ou significativas cientificamente, comparando o Modelo de Mudança Conceitual de Posner (1982) à mudança de paradigma, proposta por Kuhn (1962).

De acordo com Hewson e Thorley (1989), o que define a mudança conceitual é o processo onde a concepção do aluno perde status para a concepção apresentada pelo professor no processo de ensino em sala de aula.

Uma das criticas apontadas por Mortimer, se refere à estratégia de ensino por mudança conceitual considerada pouco efetiva e que os alunos não abandonam suas concepções anteriores ao construírem uma nova concepção. Sendo assim sugere o processo de evolução conceitual, que possibilita a modificação de perfis conceituais, onde cada perfil é formado por um conjunto heterogêneo de conceitos, formando diferentes versões para um mesmo conceito (Mortimer, 2000).

Solomon (1994) afirma que se faz necessário que a concepção alternativa e o conhecimento cientifico coexistam, pois ao impor uma nova concepção, o professor pode favorecer situações em que todos os seus alunos venham ter os mesmos pensamentos e conceitos.

O ensino por mudança conceitual, portanto não considera os fatores afetivos no processo de ensino e aprendizagem, pois ao se basear no conflito cognitivo, pode gerar insegurança, inibição e rejeição entre os alunos (Mortimer, 2000; Gil Pérez et al, 1999).

\section{A Pesquisa}

Este estudo foi realizado com 41 alunos (voluntários), de ambos os sexos, do primeiro ano do Curso de Licenciatura em Ciências Biológicas, diurno e noturno, do Campus da Unesp de Bauru, que cursavam a Disciplina de Histologia.

Para a coleta de dados, foram realizadas várias etapas. Primeiramente foi realizada uma entrevista que levantasse as principais dificuldades apresentadas pelos alunos, relacionadas ao conteúdo específico investigado (Osborne y Gilbert, 1980; Posner y Gertzog, 1982). Nesta etapa, sentiu-se a necessidade da investigação das concepções alternativas dos alunos, tendo em vista o tipo de dificuldade apresentada. Optou-se pela elaboração de um questionário que propiciasse aos alunos evidenciar suas concepções alternativas a respeito do tópico em questão. 
Dentre as várias técnicas de coleta de dados sobre as concepções alternativas, segundo Pozo (1998), tem-se o questionário e a entrevista. Este questionário pode apresentar um pequeno número de questões que estão relacionadas à entrevista inicial, que pode ser composto por questões de múltipla escolha (onde o aluno deve apresentar somente uma resposta sobre a questão proposta). Neste caso, o professor poderá perder algum tipo de informação na análise deste tipo de questionário mediante a resposta do aluno. Sugere-se então a utilização de perguntas do tipo "justifique sua resposta”, para complementar o questionário composto por questões fechadas do tipo teste. Neste trabalho optou-se pela utilização de um questionário aberto, com o intuito de propiciar a apresentação das concepções alternativas dos alunos sobre o conteúdo analisado “Tecido Muscular”.

Uma outra técnica utilizada, para o conhecimento das concepções alternativas dos alunos no processo de ensino em sala de aula, é a entrevista, que pode ser aplicada de forma individual ou em grupos de alunos. Esta entrevista visa coletar detalhes das explicações apresentadas pelos alunos, complementando aquelas apresentadas em outras técnicas como no questionário. Para isso, o professor deve elaborar um roteiro de questões que serão abordadas na entrevista, relacionada às demais atividades propostas anterior ou posteriormente. Considerando as técnicas apresentadas por Pozo, para a entrevista formulou-se uma situação problema perturbadora, elaborada a partir do contexto do aluno. A finalidade desta situação problema é de fazer com que o aluno apresente suas concepções alternativas, relacionandoas com o conteúdo a ser analisado (Pozo, 1998).

\section{Discussão e Considerações Finais}

Os alunos do Curso de Licenciatura em Ciências Biológicas da Unesp do Campus de Bauru, participantes desta pesquisa, foram analisados em diferentes aspectos e em vários momentos. A primeira forma de análise, a entrevista clínica, nos permitiu fazer um levantamento junto a esses alunos dos conteúdos inseridos na Disciplina de Histologia que apresentaram maior dificuldade de aprendizagem.

Foram várias as respostas dos alunos, que também mostraram nesta entrevista suas angústias e preocupações sobre os conteúdos que consideraram ser de difícil compreensão. A dificuldade na compreensão sobre o conteúdo "Tecido Muscular”, foi evidenciada na entrevista. No decorrer desta atividade, a entrevistadora propôs várias questões para que os alunos tentassem responder. Os alunos ressaltaram a presença de algumas organelas, estruturas celulares e até mesmo, a fisiologia da célula muscular. Neste aspecto, emitiram respostas vagas, mas que nos forneceu subsídios para definir os termos que constituem o conteúdo "Tecido Muscular" que deveriam ser investigados.

Mediante a esta entrevista, concluiuse que os alunos apresentaram uma grande dificuldade em explicar, o que ocorre em nível celular, para que ocorra o aumento da musculatura em atletas. Salientavam a sua percepção sobre esta diferença e lançavam respostas vagas para sua explicação. Conseqüentemente, foi possível concluir que esses alunos 
apresentaram deficiência na definição do formato da célula muscular, como forma de resolução a um problema proposto na entrevista. Os alunos apresentaram deficiência também na compreensão da composição e disposição das organelas dentro da célula muscular. Isto foi observado pelo fato dos alunos não conseguirem definir a localização dessas organelas na célula muscular no momento da aplicação do questionário, citando as organelas ou estruturas, sem definir sua localização.

Com relação ao questionário, que foi definido com base na entrevista aplicada inicialmente aos alunos, portanto norteado pelos aspectos mais relevantes sobre o conteúdo investigado (formato, disposição e função das organelas e estruturas da fibra muscular). Os alunos investigados através do questionário, não conseguiram definir o formato da célula muscular, evidenciando uma falta de compreensão sobre o conteúdo proposto. Os alunos conseguiram dispor algumas organelas dentro da célula muscular, porém, sem determinar sua correta localização. Muitas vezes, citaram estruturas ou componentes celulares, definindo-os como organelas independentes dentro da célula muscular, não compreendem a definição cientificamente utilizada para conceituar organelas. Por este conceito não estar bem definido, não conseguiram atribuir a estas organelas suas funções isoladamente, tampouco relacionar as funções desta organela com a fisiologia da célula muscular.

O fato dos alunos não compreenderem a localização das organelas na célula muscular e suas respectivas funções, evidencia a falta de visão tridimensional da célula. Este fato pode ser agravado, pela ausência de materiais didáticos adequados para o ensino deste conteúdo em sala de aula, pois nos livros didáticos sempre são apresentadas aos alunos, figuras bidimensionais para expor o conteúdo específico, "célula muscular".

Todas estas dificuldades apresentadas pelos alunos poderão persistir na compreensão do conteúdo investigado quando abordado em outras disciplinas, além da Histologia, como a Biologia Celular, Anatomia e Fisiologia Animal.

Com o análise de todas as dificuldades apresentadas pelos alunos, em sala de aula, o professor deve estimular seus alunos para que possam buscar respostas aos problemas propostos. Sendo assim, cabe ao professor fornecer aos alunos situações onde possam relacionar o conteúdo ministrado ao seu cotidiano, como forma de despertar o interesse da grande maioria deles, sobre a aquisição de novos conceitos.

Compreende-se que é necessário um planejamento do ensino, partindo do que os alunos já sabem, e em seguida inserir novos conceitos, fornecendo assim situações que possam ampliar suas concepções acerca de um determinado assunto, propiciando-lhes argumentos para que possam refletir sobre os fenômenos que o cercam.

Quanto mais cedo o aluno confrontar a teoria com a prática, tanto maior será o sucesso do processo de aprendizagem. E ainda, na medida em que maior for o espaço para que os alunos compartilhem suas idéias com os colegas, maior será a sua oportunidade de refletir o conteúdo ministrado sob diferentes pontos de vista.

Com relação ainda às concepções alternativas dos alunos, se estas forem 
compartilhadas com os professores e aceitas por eles, poderão ser utilizadas como ponto de partida para a abordagem de um novo conceito em sala de aula. Neste sentido, os alunos se sentirão como partes constituintes e ativas do processo de construção do conhecimento, prevalecendo o trabalho coletivo em sala de aula. $\boldsymbol{\Delta}$

\section{Bibliografía}

Andersson, B. (1986). "The experimental gestalt of causation: a common core to pupils preconceptions in science". European Journal of Science Education, Vol.8, 155-171.

Ausubel, D. P., Novak, J. D. y Hanesian, H. (1980). Psicologia Educacional, 2a. ed. Rio de Janeiro: Interamericana, pp. 96-133.

Bastos, F. (1991) "O conceito de célula viva entre os estudantes de segundo grau”. São Paulo, 109p. Dissertação (Mestrado em Educação) Faculdade de Educação, Universidade de São Paulo.

et al. (2004). "Da necessidade de uma pluralidade de interpretações acerca do processo de ensino e aprendizagem em ciência: re-visitando os debates sobre Construtivismo". En: Nardi, R. et al. (org.). Pesquisas em ensino de Ciência: contribuições para a formação de professores. $5^{\text {a }}$. ed. São Paulo: Escrituras Editora, pp. 9-55.

Brumby, M. (1984). "Misconceptions about the concept of natural selections by medical biology students". Science Education, Vol. 68, 493-503.

Coll, C., Pozo, J. I., Sarabia, B. y Valls, E. (1998). Os conteúdos na reforma. Porto Alegre: Artes médicas, pp.17-71.

Driver, R. (1986). "Psicología cognoscitiva y esquemas conceptuales de los alumnos". Enseñanza de las Ciencias, Vol. 4, f. 1, 3-15.

vista para el desarrollo del currículo de ciencias". Enseñanza de las Ciencias, Vol. 6, 109-120.

Freitas, M. y Duarte, M. C. (1990). "Ensino de biologia: implicações da investigação sobre as concepções alternativas dos alunos". Revista Internacional, Vol.3, n. ${ }^{\circ} .11 / 12$, 125-137.

Gil Pérez, D. (1983). "Tres paradigmas básicos en la enseñanza de las ciencias". Enseñanza de las Ciencias, Vol. 1.

(1986). "La metodología científica y la enseñanza de las ciencias. Unas relaciones controvertidas". Enseñanza de las Ciencias, Vol. 4, 111-121. et al. (1999). "¿Puede hablarse de consenso constructivista en la educación científica?" Enseñanza de las Ciencias, Vol.17, n. ${ }^{\circ}$ 3, 503-512.

Gilbert, J. K. (1982). “Children's science and its consequences for teaching". Science Education, Vol. 66, 623-633.

Hewson, P. W. y Thorley, N. R. (1989). "The conditions of conceptual change in the classroom". International Journal of Science Education, Vol.11, 541-553.

Kuhn, 1962

Linke, R. D. y Venz, M. I. (1979). "Misconceptions in physical science among non-science background students". Research in Science Education, Vol.9, 103-109. 
Madruga, J. A. G. (1996). “Aprendizagem pela descoberta frente à aprendizagem pela recepção: a teoria da aprendizagem verbal significativa”. En: Coll, C., Palácios, J. y Marchesi, A. "Desenvolvimento psicológico e educação, Vol. 2. Porto Alegre: Artes Médicas.

Millar, R. (1989). “Constructive criticisms. International Journal of Science Education, Vol. 11, número especial, 587-596.

Moreira, M. A. (1999). Teorias de aprendizagem. São Paulo: EPU, 195 p.

Mortimer, E. F. (1992). "Pressupostos epistemológicos para uma metodología de ensino de química: mudança conceitual e perfil espistemológico". Química Nova, Vol.15, n. 3, 242249.

. (2000). Linguagem e formação de conceitos no ensino de ciências. Belo Horizonte: UFMG, 383p.

Novak, J. (1977). Theory of education. Ithaca: Cornell University Press.

Osborne, R. J. \& Gilbert, J. K. (1980). “A method for investigating concept understanding in science". Science Education, Vol. 2, 311-321.

Piaget, J. (1971). O nascimento da inteligência na criança. Rio de Janeiro: Zahar Editores.

(1977). A linguagem e o pensamento da criança. Lisboa: Moraes.
Posner, G. J. y Gertzog, W. A. (1982) “The clinical interview and the measurement of conceptual change". Science Education, Vol.66, 195-209.

Pozo, J. I. (1998). “A aprendizagem e o ensino de fatos e conceitos”. En: Coll, C. et al., Os conteúdos na reforma. Porto Alegre: Artes médicas, pp. 17-71.

Santos, M. E. V. M. (1998). Mudança conceitual na sala de aula: um desafio epistemologicamente fundamentado. Lisboa: Livros Horizonte, 262p.

Simpson, M. y Arnold, B. (1998). “The inappropriate use of sub-sumer in biology learning”. European Journal of Science Education, Vol.4, n. ${ }^{\circ} 2$, 173-178.

Solomon, J. (1983). "Learning about energy: how pupils think in two domains". European Journal of Science Education, Vol.5, n. ${ }^{\circ} 1,49-59$. . (1994). "The rise and fall of constructivism". Studies in Science Education, Vol. 23, 1-19.

Tonolli, C. T. M. (2000). "Evolução conceitual em alunos do $3^{\circ}$ grau na disciplina biologia celular, no tópico 'membrana plasmática'. Bauru, 98p. Dissertação (Mestrado em Educação para a Ciência-Área de Concentração: Ensino de Ciências) Faculdade de Ciências, Universidade Estadual Paulista. 